\title{
КИНЕМАТИКА ЭЛЕКТРОМАГНИТНЫХ ВОЛН СЕЙСМОЭЛЕКТРИЧЕСКОГО ЭФФЕКТА ВТОРОГО РОДА В ДВУХСЛОЙНОЙ СРЕДЕ
}

\section{И.Г. Московский, Г.А. Московский ${ }^{1}$}

Саратовский государственный технический университет, кафедра прикладной математики и теории навигационных приборов

E-mail: mosig@mail.ru

${ }^{1}$ Саратовский государственный университет, кафедра петрографии и минералогии

E-mail: mosgeoal@mail.ru

На основе анализа годографов основных типов электромагнитных волн сейсмоэлектрического эффекта второго рода показана возможность применения кинематических характеристик полей этого эффекта при исследовании расположения водоносных горизонтов.

Ключевые слова: сейсмоэлектрический эффект второго рода, электрограмма, годограф при общей точке возбуждения, годограф равных дистанций, водоносный горизонт.

Kinematics of the Electromagnetic Waves from the Second-Type Seismoelectric Effect in Two-Layered Earth

\section{I.G. Moskowsky, G.A. Moskowsky}

Analysis of the traveltime curves of the principal types of the electromagnetic waves from the second-type seismoelectric effect was used to demonstrate the possibility of using the kinematic characteristics of that effect fields for studying aquifer locations.

Key words: second-type seismoelectric effect, electrogram, common-excitation traveltime curve, equal distance traveltime curve, aquifer.

Связь сейсмоэлектрического эффекта второго рода с важными петрофизическими параметрами геологической среды определяет стремление применения этого эффекта в различных задачах геофизики и инженерной геологии. Существует [1-3] три основных типа электромагнитных волн, наблюдаемых при возбуждении сейсмоэлектрического эффекта второго рода во влагонасыщенных средах. Быстрые волны - возникают на поверхности раздела сред с различными петрофизическими характеристиками и распространяются со скоростью, на несколько порядков превышающую скорость сейсмических волн. Вмороженные вол$H b l$ - распространяются в пространстве вместе с сейсмическими волнами и с такой же скоростью. Медленные волны - являются вмороженными по отношению к флюидодинамической волне порового давления, распространяющейся во влагонасыщенной среде. Все указанные типы волн наблюдаются экспериментально [4-7], поэтому представляет интерес оценка возможности практического применения кинематических и дина-

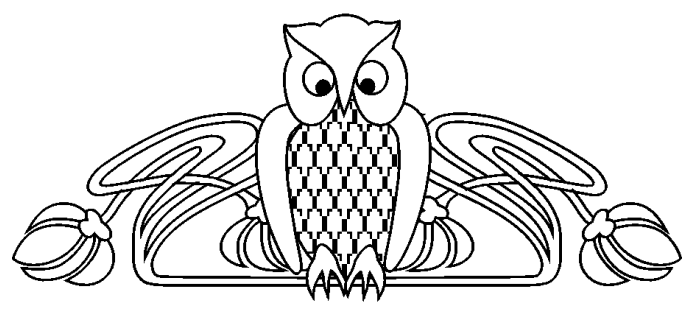

мических свойств полей сейсмоэлектрического эффекта, в частности, для установления наличия в среде влагонасыщенного слоя и определения глубины расположения его кровли. В данной работе проводится анализ кинематических характеристик электромагнитных полей сейсмоэлектрического эффекта второго рода, возбуждаемого точечным импульсным источником упругих волн в среде, содержащей водоносный горизонт.

В прямоугольной декартовой системе координат $\mathrm{O} x z$ (рис. 1 и 2) рассмотрим двухслойную модель среды, причем первый слой не содержит влаги, а второй (нижнее полупространство) влагонасыщенный. Граница между слоями влагонепроницаемая. В этой модели не учитывается влияние подошвы влагонасыщенного слоя, что можно допустить из-за сильного затухания сейсмоэлектрического сигнала с глубиной. Для изучения особенностей кинематики сейсмоэлеткрического эффекта в случае переменной глубины залегания водоносного горизонта рассмотрим два случая. В первом случае (модель 1) плоская граница между первым и вторым слоями параллельна дневной поверхности (см. рис. 1). Во втором (модель 2) граница между слоями расположена под заданным углом $\varphi$ к дневной поверхности (см. рис. 2). Точечный источник упругих волн и приёмник электромагнитного сигнала располагаются на оси $\mathrm{O} x$.

Так как в обоих моделях приёмник расположен на кровле первого невлагонасыщенного слоя, регистрироваться могут только быстрые волны. Однако, как отмечено в [3], при возбуждении сейсмоэлектрического эффекта в двухслойной среде с плоскопараллельными сухим первым и влагонасыщенным вторым слоями и влагонепроницаемой границей между ними (приемник расположен на дневной поверхности) на электрограммах (аналог сейсмограмм) прослеживаются три годографа электромагнитных волн. Первый годограф (волна 1) соответствует быстрой волне, возбуждаемой упругой волной на границе слоев в точке, находящейся на кратчайшем расстоянии от источника упругих волн. Волна 1 регистрируется практически одновременно на любом удалении приемника от источника упругой волны. Второй годограф (волна 2) соответствует быстрой волне, возбуждаемой упругой волной на границе слоев в точке, находящейся на кратчайшем расстоянии до точки расположения приёмника электромагнитного сигнала. Волна 2 распространяется со 


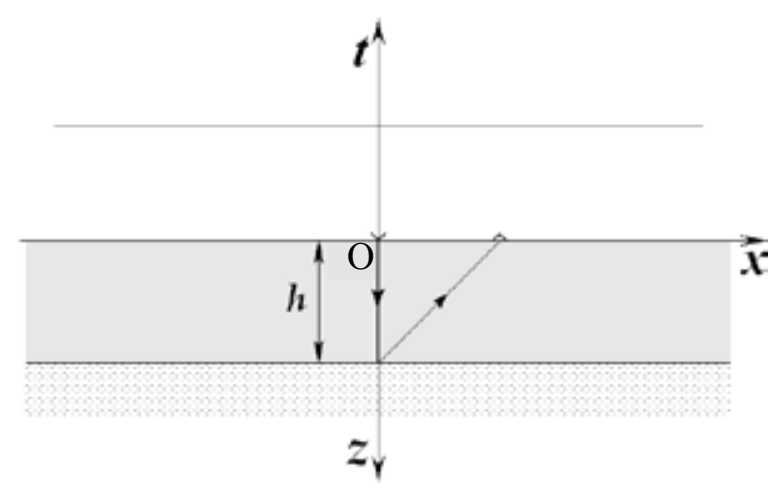

$a$

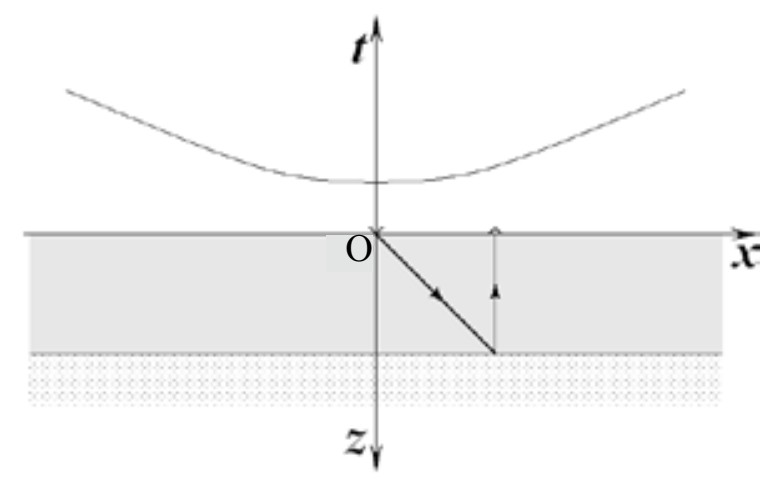

$B$

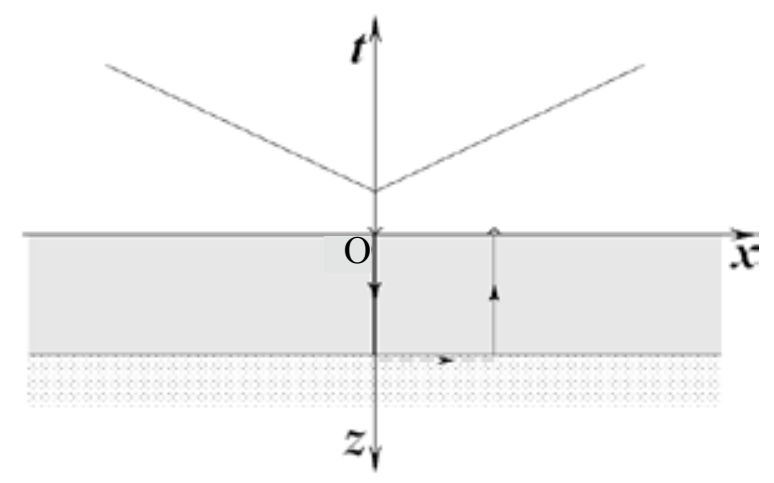

$\partial$

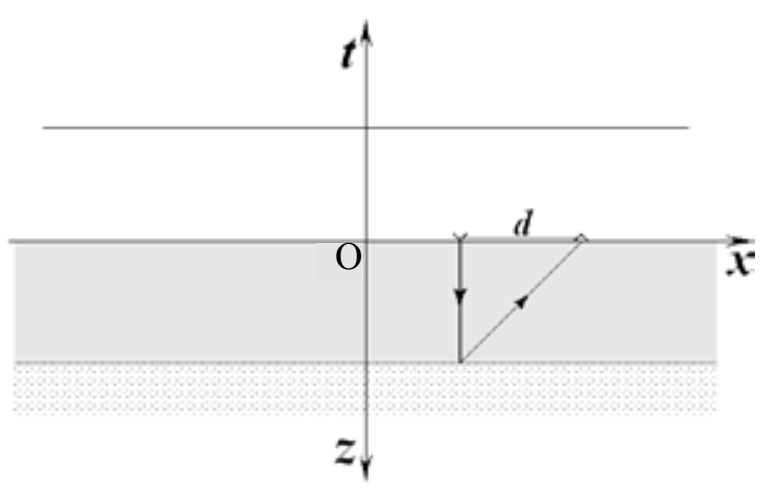

6

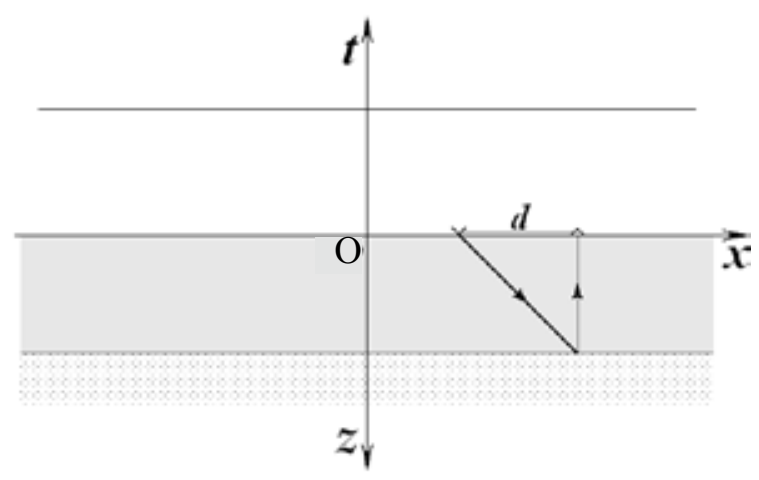

2

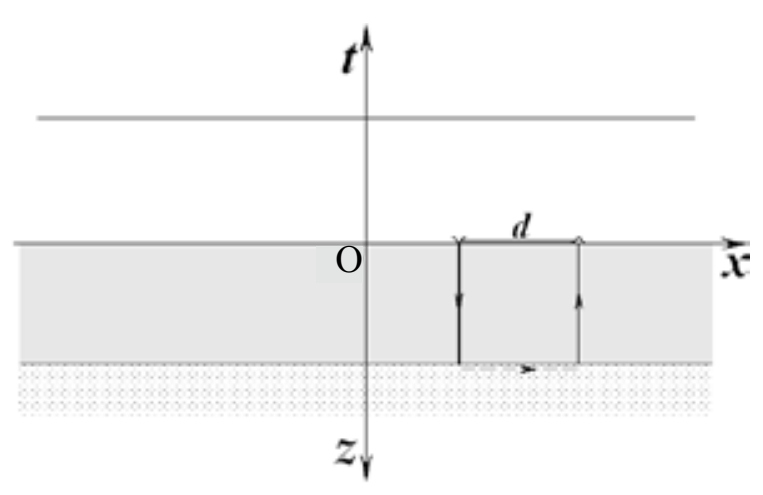

$e$

Рис. 1. Годографы для модели 1: $a$ - волна 1 (ОТВ); 6 - волна 1 (РД); в - волна 2 (ОТВ); 2 - волна 2 (РД); д- волна 3 (ОТВ); $e$ - волна 3 (РД)

скоростью упругой волны в первом слое. Третий годограф (волна 3) соответствует быстрой волне, возбуждаемой флюидодинамической волной порового давления на границе слоев в точке, находящейся на кратчайшем расстоянии до точки расположения приемника электромагнитного сигнала. Заметим, что волна порового давления начинает распространяться вдоль границы слоев в момент, когда упругая волна достигает этой границы по кратчайшему пути. Волна 3 распространяется со скоростью волны порового давления.

Для иллюстрации кинематических свойств волн 1, 2 и 3 построены годографы вдоль оси $\mathrm{O} x$ при общей точке возбуждения (ОТВ) и годографы равных дистанций (РД) вдоль оси О строении годографа ОТВ положение источника 


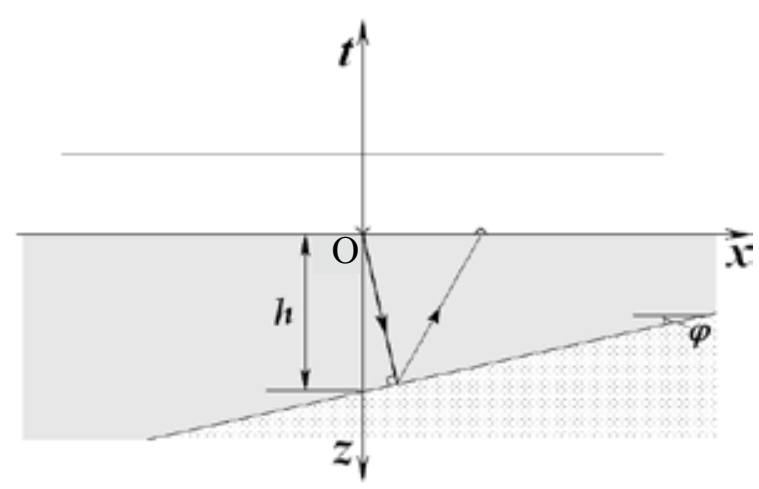

$a$

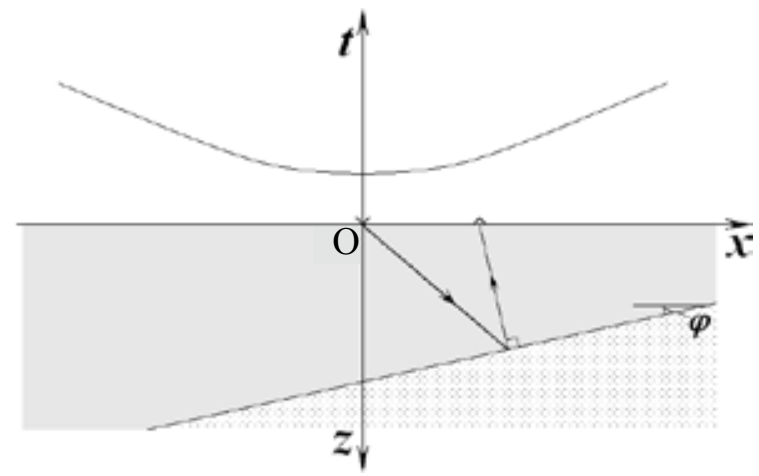

B

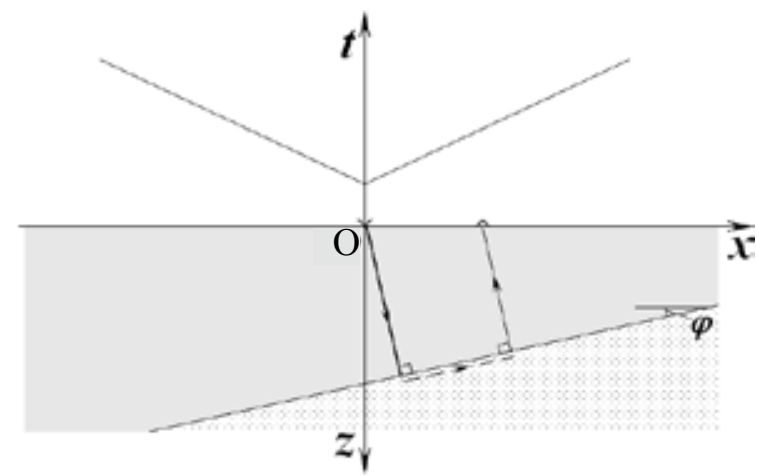

$\partial$

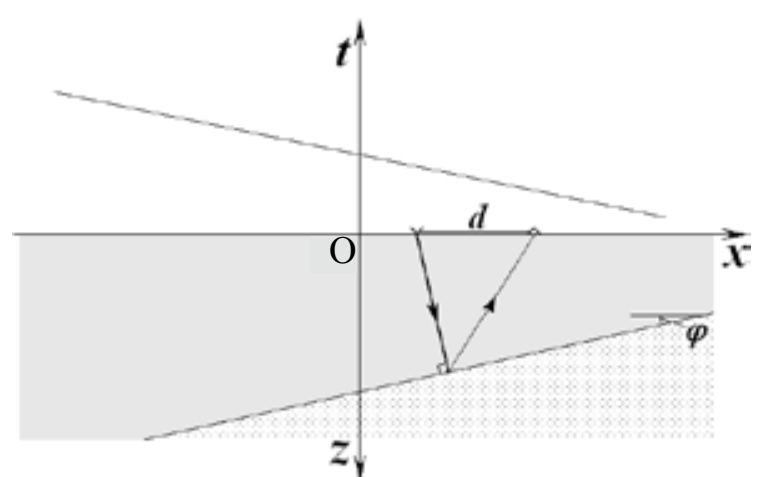

$\sigma$

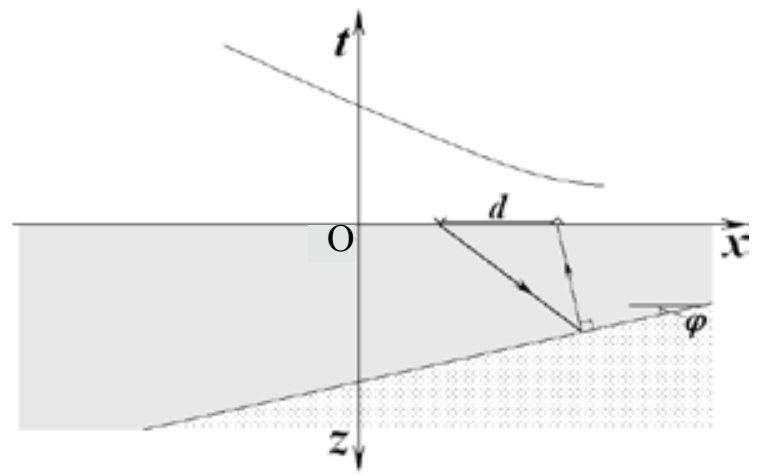

2

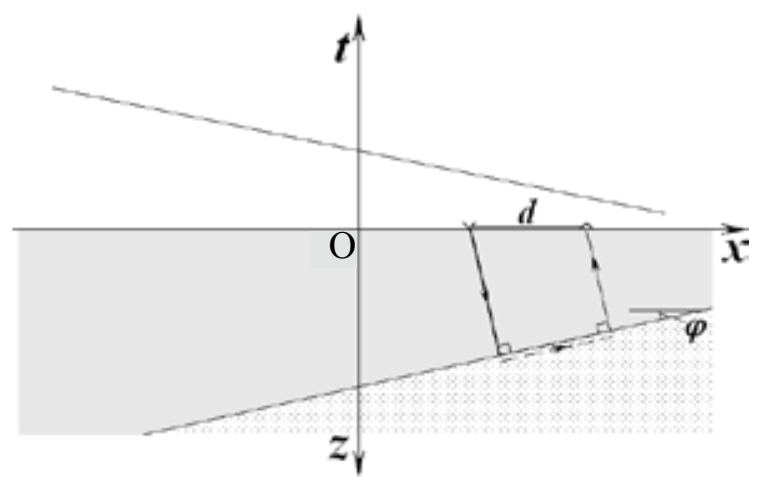

$e$

Рис. 2. Годографы для модели 2: $a$ - волна 1 (ОТВ); 6 - волна 1 (РД); в - волна 2 (ОТВ); г - волна 2 (РД); д - волна 3 (ОТВ); $e$ - волна 3 (РД)

упругих волн фиксировано в точке О, а приемник электромагнитного сигнала перемещается вдоль оси Оx. Для получения годографа РД и источник, и приемник перемещаются вдоль оси О расстояние между ними фиксированное и равно $d$. Обозначим также: $t(x)$ - время между моментом возбуждения упругой волны и приемом в точке $x$ электромагнитного сигнала, порожденного сейс- моэлектрическим эффектом; $v$ - скорость упругой волны в первом слое; $v_{M}-$ скорость волны порового давления, распространяющейся по границе между первым и вторым слоем; $h$ - глубина залегания влагонасыщенного слоя в точке $x=0$.

В таблице приведены формулы, определяющие годографы ОТВ и РД для волн 1, 2, 3, наблюдаемых при сейсмоэлектрическом эф- 
фекте второго рода в моделях 1 и 2. По данным формулам построены годографы (см. рис. 1 и 2) в системе координат Оxt. Кроме того, на рис. 1 и 2 изображены схемы распространения волн сейсмоэлектрического эффекта: сплошной толстой линией - упругая волна, сплошной тонкой линией - электромагнитная волна, пунктирной линией - волна порового давления.

Формулы для годографов ОТВ и РД

\begin{tabular}{|c|c|c|c|}
\hline \multirow{2}{*}{$\begin{array}{c}\text { Мо- } \\
\text { дель }\end{array}$} & Тип волны & \multicolumn{2}{|c|}{ Годограф } \\
\cline { 2 - 4 } & Волна 1 & $t(x)=\frac{h}{v}$ & $t(x)=\frac{h}{v}$ \\
\cline { 2 - 4 } 1 & Волна 2 & $t(x)=\frac{1}{v} \sqrt{x^{2}+h^{2}}$ & $t(x)=\frac{1}{v} \sqrt{d^{2}+h^{2}}$ \\
\cline { 2 - 4 } & Волна 3 & $t(x)=\frac{h}{v}+\frac{|x|}{v_{M}}$ & $t(x)=\frac{h}{v}+\frac{d}{v_{M}}$ \\
\hline \multirow{2}{*}{2} & Волна 1 & $t(x)=\frac{h \cos \varphi}{v}$ & $t(x)=\frac{1}{v}(h \cos \varphi-x \sin \varphi)$ \\
\cline { 2 - 4 } & Волна 2 & $t(x)=\frac{\cos \varphi}{v} \sqrt{x^{2}+h^{2}}$ & $t(x)=\frac{\cos \varphi}{v} \sqrt{d^{2}+(h-x \operatorname{tg} \varphi)^{2}}$ \\
\cline { 2 - 4 } & Волна 3 & $t(x)=\cos \varphi\left(\frac{h}{v}+\frac{|x|}{v_{M}}\right)$ & $t(x)=\cos \varphi\left(\frac{h}{v}+\frac{d}{v_{M}}\right)-\frac{x \sin \varphi}{v}$ \\
\hline
\end{tabular}

Сравнительный анализ полученных результатов (см. таблицу и рис. 1,2$)$ позволяет утверждать, что более информативными являются годографы РД. Действительно, годографы ОТВ качественно неотличимы для среды с плоскопараллельными границами (см. рис. $1 a, b, \partial)$ и среды с наклонной границей (рис. $2 a, b, \partial$ ). Более того, годографы ОТВ симметричны относительно точки расположения источника упругих волн (точка О), что не позволяет определить направление погружения влагонасыщенного пласта. Годографы РД (см. рис. $1,6,2, е$ и рис. $2, б, 2, e)$ практически повторяют форму границы между слоями. Формулы, представленные в таблице, в совокупности с дополнительной информацией о первом слое среды позволяют получать сведения о глубине залегания и наклоне водоносного горизонта.

В случае если на электрограммах сейсмоэлектрического эффекта прослеживается волна 3, то согласно [3] граница между слоями является влагонепроницаемой. Следовательно, влагонасыщенный слой перекрыт плотными непроницаемыми породами. Кроме того, по годографам волны 3 и формулам из таблицы можно оценить величину скорости $v_{M}$ волны порового давления, которая зависит от петрофизических параметров влагонасыщенного пласта. Изменение величины $v_{M}$ по изучаемому профилю может давать дополнительную косвенную информацию об измене- нии таких характеристик водоносного пласта, как проницаемость, пористость, влагоемкость и другие.

\section{Библиографический список}

1. Светов Б.С. К теоретическому обоснованию сейсмоэлектрического метода геофизической разведки // Геофизика. 2000. № 1. С. 28-39.

2. Губатенко В.П., Светов Б.С., Московский И.Г. Электромагнитное поле механо-электрического происхождения в пористых влагонасыщенных горных породах. II. Расчеты в горизонтально-слоистых средах // Физика Земли. 2002. № 2. С. $34-50$.

3. Московский И.Г., Губатенко В.П., Светов Б.С. Типы электромагнитных волн, порождаемых сейсмоэлетрическим эффектом второго рода // РГЖ. 2002. Вып. 25-26. С. 4-7.

4. Светов Б.С., Агеев В.В., Александров П.Н. и др. Некоторые результаты экспериментальных полевых сейсмоэлектрических исследований // Геофизика. 2001 . № 6. С. 47-52. 5. Butler K.E., Russell R.D., Kepic A.W., Maxwell M. Measurement of the seismoelectric response from a shallow boundary // Geophysics. 1996. Vol. 61, № 6. P. 1769-1778.

6. Mikhailov O.V., Haartsen M.W., Toksöz M.N. Electroseismic investigation of the shallow subsurface: Field measurements and numerical modeling // Ibid. 1997. Vol. 62, № 1. P. 97-105. 7. Russell R.D., Butler K.E., Kepic A.W., Maxwell M. Seismoelectric exploration // The Leading Edge. № 16. P. 1611-1615. 